American Journal of Agricultural and Biological Sciences 7 (2): 224-231, 2012

ISSN 1557-4989

(C) 2012 Science Publications

\title{
Water and Food Security for Poverty Alleviation
}

\author{
${ }^{1}$ Rabiul Islam and ${ }^{2}$ Chamhuri Siwar \\ ${ }^{1}$ School of Economics, Finance and Banking, College of Business, \\ Universiti Utara Malaysia, 06010 Sintok, Kedah Darul Aman, Malaysia \\ ${ }^{2}$ Institute for Environment and Development (LESTARI), \\ Universiti Kebangsaan Malaysia, 43600 UKM, Bangi, Darul Ehsan, Selangor, Malaysia
}

\begin{abstract}
Problem statement: This study considered the issue of water security and food security for the poor towards sustainable livelihoods. Involvement of water organization to scarceness mitigation means that it stands an essential for movements that type water more manageable for poor people. Propoor water and food authority, enhanced contact towards worth water and sustenance services, propoor financial development and maintenance development, public capability constructing and authorization, adversity preclusion and vindication and management of the environment have been recognized as a context for deed to develop water safety and food security for the poor. Approach: The study has three parts. Firstly, we considered the case for water security. Secondly, we addressed the food security for the poor. Thirdly, we suggested the progress of maintainable livings for the poor. Results: The analysis of this study was to focus and simplify the issues reported in the literature surrounding water security and food security for the poor. Conclusion: We concluded with some recommendations about the types of data around which water security and food security for the improvement of sustainable livelihoods of the poor might be designed.
\end{abstract}

Key words: Poverty alleviation, water security, food security, sustainable livelihood

\section{INTRODUCTION}

The food production growth of the world has decreased compared than population growth during the last half century. The global food price has been increasing day by day. Population growth is increasing in geometric rate and food production is growing at an arithmetic rate in the world. A latest World Bank knowledge recognizes that organizational tuning sequencers in Sub-Saharan Africa is not creating a viable resource retort in farming (Donovan and Limwado, 1996; Abdelhak et al., 2012).

Poverty and Food Security are being given increasing attention all over the world. The Millennium Improvement Goals (MDGs), which were declared in the 2000 Millennium Announcement of the United Nations, have been widely accepted as the framework to measure development actions and development progress today. As poverty is mostly found in rural areas, agricultural and rural developments are seen as being essential parts of any strategy to reduce hunger and poverty (UNDP, 2003).

The internal political dimension of food security became glaring during and immediately after the
Second World War. Food became an instrument of power and Government must be concerned with how to raise its production (Ghaly and Alkoaid, 2010). Food is the most fundamental human need. Adequate nutrition has been globally recognized as a fundamental human right. Ideally, the whole population should have the contact to adequate amount and value of food at all times.

Water-scarcity cannot be dignified by exploratory bodily water assets or entries/drainages; idea/revive stabilities unaided, since it is the qualitative, socioeconomic and political factors which in fact have the supreme impression of a water-scarcity in utmost spaces (WWAP, 2003). Indeed, the socioeconomic influences are probable to develop progressively significant as the belongings of weather variation on water assets become more Spartan (Vorosmarty et al., 2000). To measure water-poverty, one must look beyond the accessibility of the bodily resource itself and scrutinize how water is used, achieved and united (Sullivan, 2002).

Water is recycled in both productive and consumptive deeds besides paying to rustic and city

Corresponding Author: Rabiul Islam, School of Economics, Finance and Banking, College of Business,

Universiti Utara Malaysia, 06010 Sintok, Kedah Darul Aman, Malaysia 
occupations in composite conducts. Crop and livestock manufacture, agro-processing, casting, bio-networks, regeneration and humanoid fitness are all prejudiced by the value and amount of accessible water. In several cases, deprived persons do not require contact with enough water for both producers and consumptive practices, simply because the supply is bodily infrequent (Molden, 2007). This is referred to as economic water scarcity. Difficulties of misconduct of water assets also pay for poverty, as is the case with groundwater overdraft. Droughts, floods and changes in water allocation have also surged poverty and vulnerability (Carter et al., 2007).

Agronomic postponement is no lengthier just about to refining produces and manufacturing sustenance. Given the fact that, the enormous amount of survival agriculturalists has to fight of scarcity, this scarcity is not just monetary scarcity but no inquiry it is the utter significance or significance of other types of deficiencies as, evidence deficiency, aptitude and capability poverty and ethnic poverty in the first place.

Scarceness relics obstinately high and touches the lives of up to about $40 \%$ of the population (OECD, 2007). Scarceness is the main typical of South Africa's rural areas. Not surprisingly, poverty levels in rural areas are often double those in urban areas. According to Butt (2006), one in ten South Africans is undernourished, one in four children is underdeveloped and $45 \%$ of the population live on less than $\$ 2$ a day. He added points out that, in 1999, it was assessed that around $45-55 \%$ of all South Africans lived in circumstances of poverty.

Malaysia needs to achieve sustainable food security in order to afford a long-term clarification to the challenges of fighting starvation and starvation, extenuating sustenance value instability, water scarcity and defensive the atmosphere. It will need, however, a fundamental variation in prevailing strategies in order to strengthen presently disjointed systems of innovation and to surge the assets for agronomic progress and viable supply managing, with productivity gains that benefit both people and the environment.

The goal of this learning is to obtain the analysis of the issues reported in the literature surrounding water security and food security for the poor for sustainable livelihoods and to regulate the character of the connection between the water for scarceness and sustenance security.

\section{MATERIALS AND METHODS}

The analysis of this study is perceived from the secondary sources. It has been collected from the government documents and scholarly publications provided information on water and food security for scarceness improvement in the context of viable occupations.

In this study, the sectors will be discussed in the following:

- Water security

- Food security

- Poverty alleviation

- Sustainable livelihoods

\section{RESULTS AND DISCUSSION}

Water security: Water security is that persons as well as societies need consistent and passable contact to aquatic to encounter their diverse necessities, remain endangered from water linked risks and have fair reserve where fights over water rise. Deprived persons requisite contact to aquatic for creative usage to support afford a maintenance, such as irrigation or physical farming. The necessity to develop the influence of aquatic managing to scarceness decrease the necessity for movements that type water more available to deprive persons. There are six main parts have been recognized as a structure for achievement to progress water sanctuary and food security for the poor (Frans and Soussan, 2004).

Pro-poor water governance: Supremacy is strained as a vital topic through the deliberations on the water and scarceness. Worthy domination will be contingent on investors consuming the information and services desired in water organization. There is a necessity to change the rules and strategies more intelligible and reliable, to certify that government interventions in specific are improved fortified to reply to an encounter the requirements of deprived persons. Three key basics of the governance framework can be recognized (Black and Hall, 2003):

- Broader low-cost and civilization: It includes the assembly of civilization and the environment of involvement and the fate of domestic civilization, the forte of associations at diverse stages of civilization from the indigenous to the state, the formation and success of management organizations and radical contribution, the assembly and vigor of the low-cost, the accessibility of diverse services, services, infrastructure, teaching and broadcasting amenities

- Water rules, strategies and societies: It includes normal privileges that are often not officially renowned but are of key positions in the water executive 
Developed entrance to worth water amenities: Measuring the value of amenity endowment embraces watching at both measures and worth of aquatic, through the final existence particularly essential for internal supply. Access is strong-minded by a varied assortment of influences including (ADB, 2003):

- $\quad$ Privileges and prerogatives of deprived societies to practice the assets

- Ability to pay

- Appropriate knowledge and skills among the poor

- Institutions that are accessible to the poor

Pro-poor financial development and livelihood improvement: Eliminating scarcity stands finally around generating an atmosphere that determination permit the underprivileged to practice their abilities and to progress improved and further protected maintenances, which is in seizure liable on the broader practice of financial growth and on motivated actions to sustenance and progress the livings of the underprivileged. Three key elements of maintenances necessity to be measured if developed aquatic organization is to pay for viable occupation growth (Calaguas and Francis, 2003):

\section{Capital assets:}

- Livelihood activities

- Livelihood outcome

Water management theaters a main portion in various characteristics of these maintenance procedures and in specific is indispensable to numerous livelihood actions, both creative-such as agronomy and developedand family preservation actions.

Community capacity building and empowerment: The significance of certifying the contribution of deprived persons in water management has been strained through this learning and certainly is scarcely a combative concern. There are three important matters in rotating this attitude into exercise (Shrestha, 2003):

- Contribution created on a procedure

- Capacity development

- $\quad$ Funding and Implementing agencies

Authorization of straight investors needs that the period and energy they participate be consistent by upsurges to their policy-making control, with realizing activities and finance supports merging to improve the real ability to the deprived societies.
Disaster preclusion and extenuation: Disasters, whether natural or man-made, may distress extended tenure energies to decrease scarcity and the shape maintainable developments in the maintenances of the underprivileged. Several deprived persons exaggerated by such adversities is growing quickly and movements such as improved heaviness on assets and climate change suggest that these hazards will remain to develop. There is a two way street in this issue:

- The underprivileged are straight susceptible to water linked exposures, the reduced availability of resources as a result of ecological dilapidation and several forms of susceptibility that unswervingly and tortuously touch their entrance to water assets and therefore their maintenances

- Improved water organization can decrease susceptibilities. It can do so unswervingly, by declining the influence of inconsistency in water availability or providing protection against hazards

Management of the environment: Water management wants to deliberate the changeability of water movements over ecologies and the minimum movements desired to remain the reliability of these environments to evade disorderly provision movements and to sustain the sustainability of the ecosystems (IUCN, 2002).

Food security: The concept of food security means that it remains a condition that occurs when all persons must bodily, public and financial entrance to enough, innocuous and beneficial diet that encounters their nutritive requirements and food likings for any vigorous and strong existence. Sustenance safety contains at a minimum: the equipped obtainability of nutritionally passable and harmless nourishments and a secure aptitude to obtain satisfactory foods in socially conventional ways. Sustenance safety is a vital component of whole social welfare (Hussein et al., 2003).

Scarceness, food insecurity and liability remain strictly linked thoughts and their connotations need to remain simplified on the inception. Sustenance safety, sustenance timidity and liability are features or associates of scarceness. Sustenance insecurity remains a condition that occurs when persons absence protected entrance to enough quantities of innocuous and healthful food for standard development and progress and a vigorous and vigorous Lifecycle. Sustenance sanctuary may be noticed at four levels: the international, national, local and single levels which are shown in Fig. 1. 


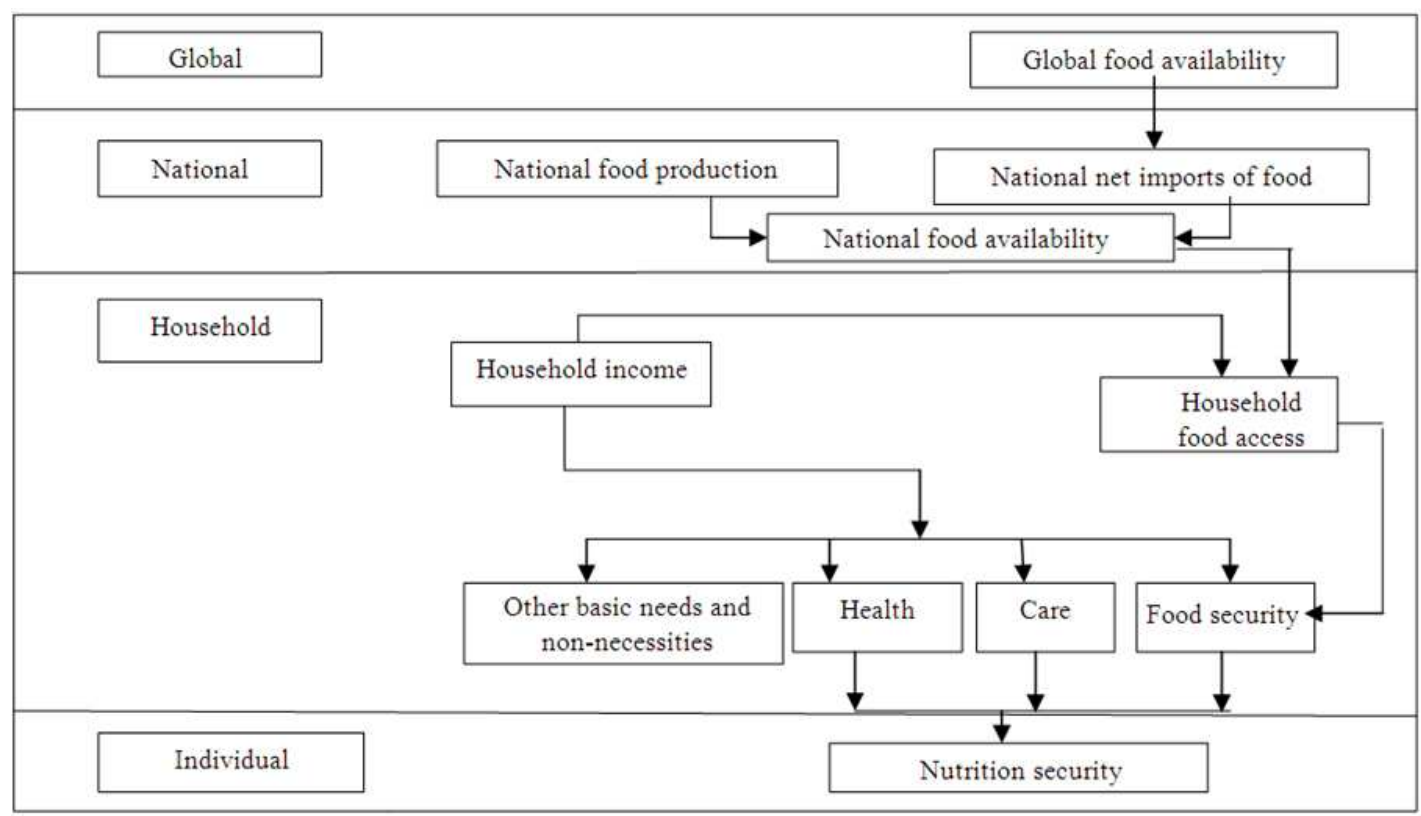

Fig. 1: Context for sympathetic food security Source: Adapted from FAO

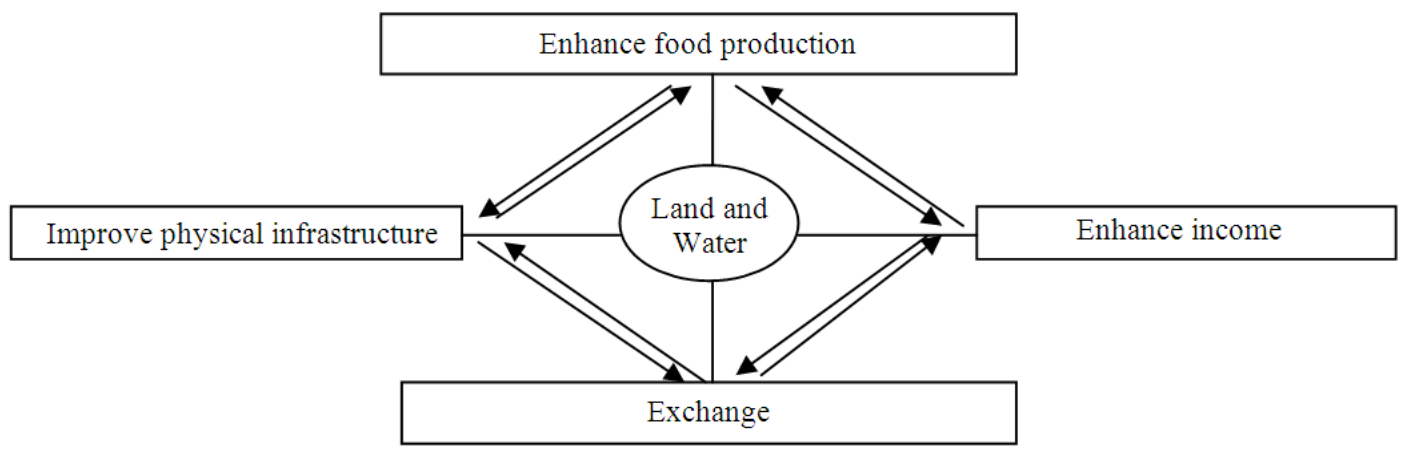

Fig. 2: Interventions for improving food security Source: Adapted from FAO

Figure 1 bounces a broadly approved upon theoretical context for sustenance safety. It spectacles in what way general sustenance accessibility mechanism over sustenance sanctuary to eventually effect dietary safety, which is ample nutritious grade scheduled a viable sources. As is healthily recognized, sufficient sustenance accessible at a general level remains only an essential situation for families to have entrance to diet but it is not an adequate situation. Families necessity also ensures the essential assets to obtain that diet and all at once encounter further elementary requirements. Lastly, sustenance sanctuary mechanisms ended people's food consumptions to impact their diet safety.

Key approaches to addressing the problem: In order to reach achievement policies to eliminate the diet insecurity need to attack these fundamental reasons by merging the struggles of those who effort in varied areas such as farming, food, fitness, teaching, social well-being, economics, public mechanism and the environment. The reasons of nutriment diffidence propose that four main involvements can be recycled to progress food security. Interventions for improving food security are shown in Fig. 2.

The first involvement encouragements sustenance safety by improving farming manufacture. The small homestead area needs to be the focus of this determination. A number of lessons reveal that farms generally realize improved vigor relations than higher ones. Small holder household plantations also deal superior influence on relieving scarcity, starvation and redundancy. Furthermore, small holder agriculturalists 
who practice irrigation usually attains much better profits than their rainfed complements. The second involvement is pointed at refining the procuring influence of the underprivileged by creating further engaging prospects and endowing the pitiable. The third involvement is to enable interchange of properties and amenities by the underprivileged. This encompasses generating an allowing situation for the reduced to occupy in marketplace dealings as sellers and buyers of properties and amenities through real rules and societies.

The fourth involvement includes organization progress such as establishment of irrigation amenities, improvement of the rural transportations to entrance marketplaces and facility of energy.

Sustainable livelihoods: An employment encompasses the abilities, properties and deeds essential for a means of living. An occupation is viable when it can manage with and improve from strain and tremors and will preserve or improve its abilities and properties both now and in the future, while not understanding the natural asset base (Carney, 1998).

Understanding the sustainable livelihoods: The idea of maintainable maintenances is realized as acute to empathetic the connection between scarceness and water safety. It has been steadily emerging terminated the last era to a site where it exists broadly recognized as contribution novel understandings into the diminuendos of growth and the variety of involvements of the deprived persons through the sphere. It stands an attitude which is supple and active and in specific that delivers a source for empathetic the connection among deprived societies, their homegrown location and external socioeconomic, ecological and organized services.

Rennie and Singh (1996) maintain that mostly the deprived persons of the world are contingent unswervingly on typical assets, finished gardening, steering, gathering or stalking for their occupations. Therefore, for the livings be maintained, the natural assets must be continuous. An insufficient facts may exemplify in what way this attitude assistances in the progress of actions that focus on the associations between aquatic, scarceness and maintainable maintenances.

Maintenances remain composite, with families in the evolving world responsibility a wide variety of actions: persons are not just agriculturalists, or workers, or workshop employees (Carney, 1998).

Maintenances are inclined by a variance change of outside services: societal, financial, radical, legitimate ecological and formal, both within and external the zone in which a family survives, that are elsewhere the governor of the intimate (Soussan and Frans, 2003).

The link between the altered components of livelihoods subtleties recognized are shown in Fig. 3.

Capital assets: People attraction on a set of capital properties as a source intended for maintenances. Carney (1998) recognizes the elements of five livelihood assets: mortal, ordinary, monetary, bodily and societal. Maintenances are erected from a sequence of selections ended the usage of these properties. For public stuff assets for instance water in specific, a main problem is the organizations of privileges over which societies, particularly the pitiable, advantage entrance to these properties: that is legitimate, public and other influences that edict that is capable to attract upon the assets.

Livelihood activities: Associates of the family motivation assume a series of maintenance actions raising a crop, casting in a stream, salaried for somebody different, or creating pots. Some actions might be leading but it is infrequent for a domestic and particularly for deprived persons rustic families, to trust solely on one and most association complex sets of actions in their livings.

Income: These actions will produce pay for the domestic properties, amenities and money which are then owed in four leading ways: re-circulated as inputs into maintenance events; public recompense: tariffs, attention to advances, participated to sustain the maintenance properties vile; expended: diet, accommodation, clothes and all the other properties and amenities that pay for the physical value of Lifecycle of the family.

Local and external factors: Numerous indigenous and outer issues impact livings, including marketplaces, the bodily atmosphere and the societal and radical situation. These structures can be themselves integrally energetic and livings are susceptible to the tremors and leanings in these issues that are elsewhere their instant control. The impression of these outside shock waves and learnings will fluctuate from family to family.

Vulnerability: Vulnerability is composed a complaint and a factor of scarceness and mentions to the aptitude of persons to evade, survive, or convalesce from the damaging effects of issues that interrupt their subsists and that are outside their instant governor. This contains both tremors (abrupt variations such as natural 
calamities, warfare, or falling market values) and inclinations (ecological humiliation, repressive radical schemes, or worsening expressions of employment). These susceptibilities touch dissimilar families very inversely.

Water in the maintenances of the underprivileged: Safeguarding that deprived societies have contact with water properties takes developed widely associated with certifying. Deprived persons are contingent upon water in four significant behaviors: as an input into manufacture, for the preservation of fitness and wellbeing, to certify the environments reliability and to decrease susceptibility to exposures (Carney, 1998).

Water as an input into production: Water assets are vigorous efforts into maintenance creation actions in an extensive diversity of conduct. Farming is the utmost understanding, as in many rustic societies agronomic invention is the base of the budget and the feasibility of farming are thoroughly related to consistent contact with water. It is rain-fed farming that grants the most difficult contests in refining the possibility of water in the maintenances of the underprivileged. This is for two causes: extra deprived persons livings are needy upon rain-fed farming and the efficiency of this farming is distant further delicate in the expression of mutable precipitation (Hussein and Nelson, 1998).

There are numerous other creative actions that be contingent on aquatic as a main effort, counting casting, sapling and allotment farming around farmsteads. These numerous events may be the leading cradle of maintenances for underprivileged families, through this principally the situation in coastline area, swamps and about tarns, dry zones and hilly zones.

Water for fitness and cleanliness: The fitness and well-being circumstances of the underprivileged, mainly of susceptible clusters, for example offspring, the mature and the womenfolk in overall are diligently linked to the running of passable, harmless and reasonable water stores. The privation of these provisions is one of the leading explanations for hostile fitness and untimely demise among the biosphere's humblest societies (Davies, 1996).

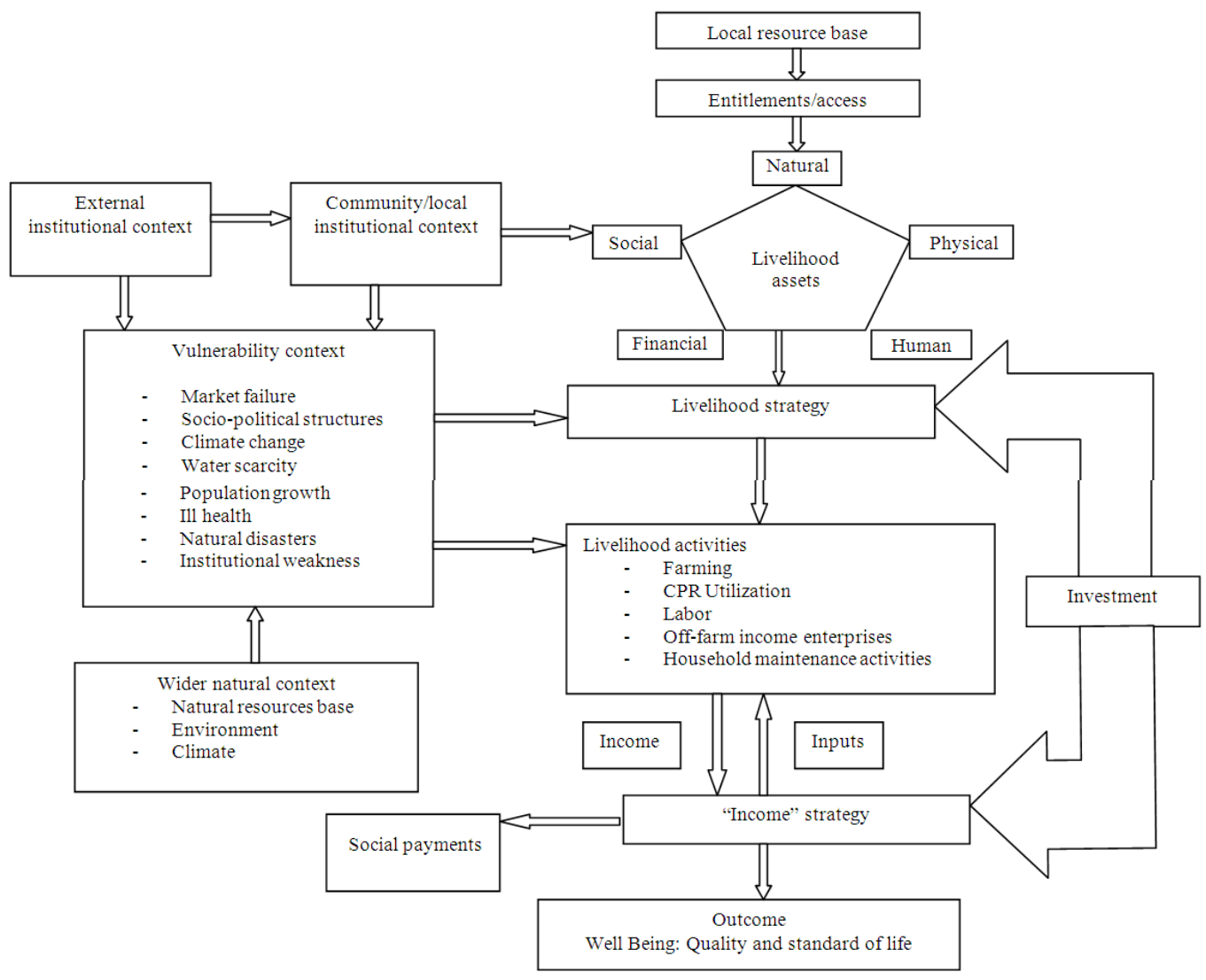

Fig. 3: A model of livelihoods dynamics Source: Adapted from FAO 
Ecosystems in the livelihoods of the poor: The movement and the value of water is serious for the practicality of the ecologies over which the underprivileged improvement entrance to the usual assets that are the basis of several features of their maintenances. The preservation of the honesty of these environments is precarious for scarcity lessening and the conservation of livings as much as for their environmental implication. Not least of the properties that vigorous environments afford is the water itself, with the movements of passable and ethical value water for the manufacture and consumption usages being mostly a replication of the ailment of the ecologies over which its movements (Carney, 1998).

\section{CONCLUSION}

Based on the exploration, the homework accomplishes that entrance to water has momentous influences on sustenance security and scarceness lessening. Water (irrigation) organization may support certify sustenance safety and kick together farmstead and non-farm families out of enduring or lingering deficiency by growing efficiency, employ, earnings, as well as payments and tortuously by attractive associated financial actions. Poor conservation may clue to reduce water provisions and disprove any positive impression on poverty alleviation. Plummeting scarcity and sustenance timidity is not only solely an inquiry of attractive agrarian efficiency and manufacture or by creating more revenue; it is important to lecture formal, radical and financial issues that incline to eliminate persons and inhabitants clutches from development.

The four ranges in which water possessions stimulus the maintenances of deprived persons recognized water organization: irrigation and other categories of water delivery for industrious actions, national water resource and cleanliness, environments organization and adversity controlling and extenuation. A maintenances method for water organization will imitate this and improve an included attitude at the indigenous level. Water management shows a significant part in numerous features of livelihood processes and in specific is vital to many livelihood actions: products such as farming and developments and domestic conservation actions. The method set out in this study delivers the basis for empathetic these associations. It is a method that should be dominant to the improvement of pro-poor combined water assets managing.

\section{ACKNOWLEDGEMENT}

Financial assistance provided by the research university grant UKM-MI-OUP-2011 and UKM-AP-
PLW-04-10. Institute for environment and development, University Kebangsaan Malaysia is gratefully acknowledged.

\section{REFERENCES}

Abdelhak, S., J. Sulaiman and S. Mohd, 2012. Poverty among rural communities in Kelantan and Terengganu: The role of institutions, farmers' risk management and coping strategies. J. Applied Sci., 12: $125-135$.

ADB, 2003. Development communication improves water project in Vietnamese towns.

Black, N. and A. Hall, 2003. Pro-poor water governance.

Butt, R., 2006. OCEN issue, Poverty and Rural Development, Opportunity Costs Economics Newsletter

Calaguas, B. and J. Francis, 2003. empowerment and community development.

Carney, D., 1998. Sustainable Rural Livelihoods: What Contribution can we Make? 1st Edn., Department for International Development, London, ISBN-10: 1861920822, pp: 213.

Carter, M.R., P.D. Little, T. Mogues and W. Negatu, 2007. Poverty traps and natural disasters in Ethiopia and Honduras. World Dev., 35: 835-856. DOI: 10.1016/j.worlddev.2006.09.010

Davies, S., 1996. Adaptable Livelihoods: Coping with Food Insecurity in the Malian Sahel. 1st Edn., Macmillan Press, New York, ISBN-10: 0312126824, pp: 335.

Donovan, P.A. and G.M. Limwado, 1996. The social benefits of trf's research and development on Tea in Malawi.

Frans, D. and J. Soussan, 2004. The Water and Poverty Initiative: What we Can Learn and What we Must Do. 1st Edn., Asian Development Bank, Manila, Philippines, pp: 27.

Ghaly, E. and F. N. Alkoaik, 2010. Extraction of protein from common plant leaves for use as human food. Am. J. Applied Sci, 7: 331-342. DOI: 10.3844/ajassp. 2010.331.342

Hussein, I., M. Giordano and M.A. Hanjra, 2003. Agricultural water and poverty linkages: Case studies of large and small systems. IWMI, Colombo.

Hussein, I., N. Regassa and S. Madar, 2003. Water for Food security for the poor.

Hussein, K. and J. Nelson, 1998. Sustainable Livelihoods and Livelihood Diversification. Institute of Development Studies, University of Sussex. 
IUCN, 2002. Policies for ecosystem integrity: The wetlands sector strategic plan in Uganda. IUNC.

Molden, D., 2007. Water for Food, Water for Life: A Comprehensive Assessment of Water Management in Agriculture. 1st Edn., Earthscan, London, Sterling, VA., ISBN-10: 1844073963, pp: 645.

OECD, 2007. Review of South Africa's Economy. Organization for Economic Cooperation and Development.

Rennie, J.K. and N.C. Singh, 1996. Participatory Research for Sustainable Livelihoods: A Guidebook for Field Projects. 1st Edn., IISD, Winnipeg, ISBN-10: 1895536421, pp: 122.

Shrestha, A., 2003. Building gender responsive water user associations in Nepal. ADB, Manila.

Soussan, J. and D. Frans, 2003. The role of water in the development of sustainable livelihoods of the poor.
Sullivan, C., 2002. Calculating a water poverty index. World Dev., 30: 1195-1210. DOI: 10.1016/S0305750X (02)00035-9

UNDP, 2003. Global human development report, millennium development goals: A compact among nations to end human poverty. UNDP.

Vorosmarty, C.J., P. Green, J. Salisbury and R.B. Lammers, 2000. Global water resources: Vulnerability from climate change and population growth. Science, 289: 284-288. DOI: 10.1126/science. 289.5477.284

WWAP, 2003. Water for People, Water for Life: A Joint Report by the Twenty-three UN Agencies Concerned with Freshwater. 1st Edn., Berghahn Books, Paris, ISBN-10: 1571816275, pp: 576. 